\title{
KRIEMHILD: LA ENCARNACIÓN DE LA VENGANZA EN UNA MUJER
}

\author{
Mónica Rodríguez Gijón \\ Universidad de Sevilla
}

\begin{abstract}
Goodness and Badness have always been present in man's life and in his artistic manifestations, in which we must emphasise the literature. The rage, considered as a special type of badness, appears in Nibelungenlied with a genial representation through the figure of its feminine protagonist Kriemhild. With this article it is analysed how and how far this combination can get.
\end{abstract}

\section{EL CONCEPTO DEL MAL}

Como dos polos diametralmente opuestos, el Bien y el Mal han estado presentes desde que el ser humano existe sobre la faz de la Tierra. Ya aparece así en la Biblia, cuando nada más crear al hombre, Dios le advierte de su infelicidad futura si come de la fruta prohibida, o lo que es lo mismo, si entra en conocimiento del Bien y del Mal, ya que desde ese momento será responsable de sus actos y perderá el estado de ingenuidad feliz que su Creador le ofrecía en un principio ${ }^{1}$. A pesar de las advertencias, el ser humano es imperfecto y yerra, motivo por el cual hoy día no estamos en el Paraíso sino en este Valle de Lágrimas, expiando pecados y haciendo méritos para poder volver a alcanzar ese estado idílico que sin embargo Dios nuevamente nos promete una vez terminada nuestra vida terrenal.

Mientras tanto el hombre debe protegerse del Mal, que le acecha continuamente y que se manifiesta bajo multitud de variantes, entre las que se encuentra la venganza. En esta última hay que matizar los conceptos, porque no todos los pueblos y culturas la han considerado -y todavía algunos primitivos actuales persisten en ello- con la mentalidad cristiana de un pecado, sino más bien como una medida de regulación de la justicia.

Entre estos pueblos se encuentran los antiguos germanos, cuyo concepto de la venganza difiere bastante del cristiano, que introduce el perdón y la reconciliación en sus doctrinas. Véase si no el ejemplo fehaciente en un testimonio literario alemán de la Edad Media: el Cantar de los Niqelungos. En él se narra la venganza brutal que la reina Kriemhild realizó contra los asesinos de su marido Siegfrid, llevándola hasta límites desproporcionados, tales como la caída y destrucción de todo el pueblo de Burgundia.

Así pues, resultando fascinante y al mismo tiempo abrumador semejante hecho, sería interesante analizar a través de esta obra el tratamiento de la venganza, que aunque en el mundo primitivo germánico era un medio jurídico necesario para mantener el orden en la vida diaria, sin embargo el autor del Cantar de los Nibelungos lo presenta como un acto del demonio.

' "... y le dio este mandato: "De todos los árboles del paraíso puedes comer, pero del árbol de h ciencia del bien y del mal no comas, porque el día que de él comieres, ciertamenle morirás"'.' (Génesis 2, 16-17) 


\section{EL CONCEPTO DE VENGANZA}

La palabra alemana que designa al concepto de venganza es Rache, que procede a su vez de la raíz indoeuropea *u[e]reg-, con un significado aproximado a "empujar, atosigar, ahuyentar, o perseguir de manera hostil" ${ }^{\prime 2}$.

La venganza es la satisfacción que una víctima o la familia de ésta se cobra ante un agravio recibido. En su origen fue considerado como una manera de tomar justicia uno mismo, y entronca directamente con el punto de partida en torno al cual se origina la disciplina de Derecho penal. Dentro de ella, existe un tipo especial de venganza, llamada "privada" o "de sangre" (Blutrache), que normalmente se aplica ante un delito de sangre, por el cual la víctima o sus parientes responden al agresor también con otro acto de esta naturaleza. Semejante venganza es común a todos los pueblos y se remonta a los primeros tiempos de la humanidad, cuando los individuos se reunían en pequeñas agrupaciones como la familia o la tribu, y los parientes de la víctima se solidarizaban con ella al igual que los parientes del culpable se adherían a éste. El ofendido o su familia se resarcía matando al agresor o algún miembro de su clan. El Antiguo Testamento lo dice así: "No aceptaréis rescate por la vida del homicida que deba ser condenado a muerte: ha de ser muerto"3.

Lógicamente esto dio lugar a guerras privadas que causaron la desaparición de muchas familias. Por esta razón con el paso del tiempo el derecho de venganza privada, que a veces era desproporcionado, comenzó a limitarse a través de varias medidas: en primer lugar, la ley del talión -el famoso "ojo por ojo y diente por diente"-, que consistía en no poder infringir al agresor un mal mayor que el que éste había inferido a su víctima. En segundo lugar, la composición, que es la compensación económica que el agresor debe entregar a la víctima. Y finalmente el asilo, es decir, el delincuente se ponía a cubierto de los primeros impulsos del vengador logrando la intervención de alguien que examinara el hecho.

En el mundo antiguo se tiene noticias de pueblos practicantes de este recurso, como por ejemplo el germánico, que utiliza la venganza privada como medida reguladora, y no sólo ante delitos de sangre sino también más leves. Sin embargo sobre este pueblo se conservan pocos testimonios hoy día, y lo constituyen básicamente los restos arqueológicos y textos que pertenecen a autores de la Antigüedad, que además tampoco son oriundos de este pueblo. Destáquese como documento más importante la Germania de Tácito $(98 \text { d.C. })^{4}$. En él se describe la constitución de la sociedad germánica, formada fundamentalmente por familias agrupadas a su vez en tribus que tenían gran influencia en la vida del Estado, y que eran además las encargadas de vengar las ofensas. De esta forma, el derecho consuetudinario germánico se basa en la práctica de la vendetta o venganza entre clanes y familias, así como medios para resolverlas entre los que se cuentan ordalías, juramentos y otros procedimientos, todos ellos impugnados posteriormente en los siglos XI-XII.

En muchas ocasiones las ofensas se solucionaban con pago de dinero (el conocido Wergeld). Pero no siempre se conseguía la satisfacción plena, ya que la parte dañada podía

\footnotetext{
${ }^{2}$ En medio alto alemán es räche; en antiguo alto alemán, rāhha ("Rache, Strafe"); en gótico wrekei, "Verfolgung". El verbo rächen -"vengar"-, tiene un pariente en antiguo inglés, wrecan, ("treiben, stoßen, vertreiben"), y en antiguo islandés reka ("treiben, jagen, verfolgen, werfen"), que pretenecen a la raíz indogeuropea *u/ejreg (“stoßen, drängen, vertreiben"). (Herkunftswörterbuch 1989, 567).

${ }^{3}$ Números 35,31 .

${ }^{4}$ Cuyo título original es De origine et situ Germanorum.
} 
realizar igualmente la venganza de sangre. Cada miembro del grupo tenía derecho y obligación de tomar venganza sobre el agresor, pero estableciendo una jerarquía con relación a la proximidad de parentesco, de tal manera que el primer vengador era el pariente más cercano. Este deber estaba tan arraigado en la sociedad germana, que además era hereditario. Así lo documenta Tácito en la Germania:

Suscipere tam inimicitas seu patris seu propinqui quam amicitas necesse est; nec implacabiles durant; luitur enim etiam homicidium certo armentorum ac pecorum numero recipitque satisfactionem universa domus, utiliter in publicum, quia periculosiores sunt inimicitae iuxta libertatem. (Germ. XXI. 1.) $)^{5}$

En el caso de la muerte del marido, debía ser la mujer, como ocurre con Kriemhild en el Cantar de los Nibelungos, la que debía vengar la muerte del difunto, siendo además un deber sagrado, que constituía una especie de culto a los muertos. Estaba exaltado por la religión germánica de tal manera que se convirtió en el placer de los dioses, no conociendo por ello límite de tiempo ni espacio.

La venganza puede realizarse por diferentes razones. En la mayoría de los casos, como en el ejemplo de Kriemhild, es una ofensa directa. Pero cuando la venganza la llevan a cabo otras personas, la solidaridad con respecto al ofendido es de diverso tipo. Así, por ejemplo, lo más frecuente es vengar a alguien por lazos familiares con la víctima, como es el caso del rey Sigmund con respecto a su hijo Siegfrid, o por lazos vasallales, como es el caso del guerrero Hagen con respecto a Brünhild ${ }^{6}$.

Con la llegada del cristianismo las leyes germanas cambian y al igual que muchos ámbitos del mundo germánico, se adaptan a los nuevos conceptos morales que se introducen, modificando esta manera de impartir justicia, o lo que es lo mismo, de dar a cada uno lo que le corresponde. La Iglesia no se opuso de entrada a la venganza de sangre ni a las ordalías, pero sostuvo que éstos no podían producir la salvación que venía de la fe y de las buenas obras, considerando que la persistencia en la venganza de sangre tras una razonable satisfacción era una ofensa contra Dios.

De esta manera el cristianismo influyó para que los pueblos germanos comenzaran a limitar la venganza de sangre, como lo prueba la codificación de las leyes latinas que cada pueblo germano hizo entre los siglos V y XI d.C. Así por ejemplo, en su mayoría, estas leyes intentan compensar las ofensas mediante la composición, y una de las más antiguas, la Lex burgundionum (sobre el año 500) permite el derecho de venganza solamente frente al asesino, pero no contra sus parientes.

Ya con posterioridad en los siglos XII-XIII, la venganza de sangre no está permitida, y la Iglesia intenta suprimirla basándose en pasajes del Nuevo Testamento, como este de San Pablo: "No os toméis la justicia por vosotros mismos, amadísimos, antes dad lugar a la ira (de Dios); pues escrito está: “A mí la venganza, yo haré justicia, dice el Señor”7.

\footnotetext{
5 "Es fuerza ser enemigo de los enemigos del padre o pariente, y amigo de sus amigos. Pero no duran, sin poderse aplacar, las enemistades; porque todos los agravios, y aun el homicidio, se recompensan con cierto número de ganado y toda la familia recibe la satisfacción, cosa muy útil para el bien público, porque las enemistades entre hombres que viven en libertad son más peligrosas". (Tácito, 1940: 34-37)
}

${ }^{6}$ Cfr. Holtzhauer, 1997. 
La venganza también ha sido estudiada desde otros puntos de vista. Así, los antropólogos creen que ésta era el único modo de frenar los delitos en los primeros tiempos. Esto todavía puede observarse hoy en pueblos primitivos salvajes. Con la civilización este concepto de venganza se fue perdiendo, quedando como últimos vestigios la vendetta italiana, que a su vez fue prohibida en el siglo XIX.

En psicología la venganza es una pasión que obedece a instintos de egoísmo y conservación. El individuo trata de vengarse del culpable o de todo aquello a lo que se extiende la culpa. De esta manera en principio consiste sólo en superar los sentimientos desagradables de la ofensa con sentimientos agradables de agresor. El principal sentimiento que nos mueve en la venganza es el odio, por lo que también es una forma de éste, ya que se constituye como la manifestación psíquica del acopio de asociaciones a un objeto que nos trae a nuestra conciencia continuamente la imagen del sufrimiento. La venganza además no trae buenas consecuencias, provoca contra-venganza, y no siempre sale bien, pudiendo con ello causar nuevos daños. Así pues, la venganza es a menudo una consecuencia de la cólera y del resentimiento. Surge de la experiencia del daño recibido, y su objetivo es la exaltación del amor propio que ha sido menospreciado y agraviado por la injuria sufrida.

\section{El Cantar de los Nibelungos}

\subsection{Breves consideraciones filológicas}

Del Cantar de los Nibelungos nos han llegado hoy día cerca de tres docenas de manuscritos, datados entre los siglos XIII y XVI. La obra es anónima, y aunque no se sabe nada de la persona del autor, sin embargo por las numerosas descripciones geográficas que realiza, se piensa que su lugar de origen se encuentra entre Viena y Passau. A pesar de tener un contenido relacionado con sagas mucho más anteriores, el Cantar de los Nibelungos se escribe en torno a 1200, dentro de la época caballeresca de los Staufer, teniendo como consecuencia un poema que aunque está calificado como epopeya heroica, combina elementos de las sagas de la época de las grandes migraciones con el ideal de vida caballeresco. De esta manera, el poema acusa elementos germanos como el concepto del honor -cuya mancilla supone la venganza por parte del ofendido-, la fuerza de los símbolos, o el fuerte sentimiento de unión tribal, y al mismo tiempo refleja elementos cortesanocaballerescos como el cristianismo -propio de la caballería europea-, la generosidad de los reyes con respecto a sus vasallos, la ceremonia de juramento de la espada de Siegfrid, los preparativos de las fiestas con justas y torneos, y el gusto por cultivar los buenos modales cortesanos, abarcando desde el ritual del trato con las damas hasta las normas de comportamiento entre amigos y enemigos (Lorenzo, 1994: 12).

En cuanto a la estructura de la obra, hay que decir que el centro de la acción es Kriemhild. Comienza con su sueño del halcón y termina con su muerte. La acción se divide de esta manera en dos partes fundamentales a lo largo de 39 cantos o aventuras: en una primera comienza con la petición de Siegfrid de la mano de Kriemhild, las hazañas que Siegfrid realiza en Worms para merecerla, la boda, y la vuelta a Xanten. Tras diez años, Gunther y Brünhild los invitan a Worms, en donde se produce la pelea entre las reinas que conduce a la muerte de Siegfrid y la viudedad de Kriemhild. En la segunda parte, tras trece años de reclusión llorando la muerte de Siegfrid, Kriemhild ve la posibilidad de llevar a cabo su venganza aceptando la proposición de matrimonio del rey Atila, y se marcha con él 
a tierra de hunos. Una vez allí invita a sus hermanos, con los que se establece una gran batalla que terminará con la destrucción de los burgundos y la muerte de la propia reina.

\subsection{La venganza en la obra}

El hilo principal de la obra y que une ambas partes es Kriemhild y su deseo de vengar un asesinato. Sin embargo, esta no es la única venganza que se lleva a cabo a lo largo del poema.

Ya en la aventura tercera, al narrar Hagen las hazañas de Siegfrid, cuenta cómo el héroe una vez cabalgando, encontró a los príncipes Schilbung y Nibelung disputándose un tesoro. Pidieron a Siegfrid que hiciera el reparto, pero a la hora de pagarle el favor se entabló una lucha en la que el héroe logró matarlos y someter a sus setecientos hombres. El enano Alberich, que estaba al servicio de ellos quiso vengar a sus señores, y luchó contra Siegfrid. Sin embargo, el héroe lo derrotó, le quitó un manto mágico que Alberich poseía, le obligó a jurarle fidelidad, y se llevó el fabuloso tesoro de los Nibelungos poniendo a Alberich de guardián.

Si bien este caso descrito es un intento de venganza fallido por parte de Alberich, una satisfacción que se cumple plenamente es la que tiene lugar en el camino que los burgundos realizan cuando se dirigen hacia la tierra de los hunos. Al llegar al Danubio se hace un alto en el camino porque no es un río vadeable. Hagen encuentra una barca para transportar a los guerreros y enseres al otro lado, pero ante la negativa y falta de cooperación del barquero, lucha con él y lo mata. Sus señores Else y Gelfrat quieren vengarlo ${ }^{8}$, y Hagen lucha también contra ellos. Se entabla una batalla terrible entre burgundos y bávaros. Hagen logra matar a Gelfrat, y Else se da a la fuga. Entonces se dice que a pesar de la pérdida cuantiosa de burgundos, estos se habían visto vengados porque en el bando de los bávaros la pérdida había sido mayor ${ }^{9}$.

Existe también una venganza que se reclama, pero que gracias a la intervención del rey Atila se resuelve pacíficamente y no llega al conflicto armado. Estando en tierra de hunos, los burgundos participan en los torneos que el monarca ha preparado en su honor. Todos están muy nerviosos ante las evidentes intenciones de Kriemhild, que ya ha intentado provocarlos varias veces para vengarse. Así pues, la tensión es tan fuerte que parece que de un momento a otro la lucha va a estallar. No pudiendo controlarse más, el caballero Volker arremete contra un guerrero huno matándolo, y en seguida los parientes de éste reclaman venganza. Pero el asunto se resuelve pacíficamente, ya que Atila intercede diciendo que todo ha sido un accidente ${ }^{10}$.

La venganza desencadenante de la de Kriemhild es la que Hagen previamente lleva a cabo para lavar el honor ultrajado de su señora Brünhild. La primera vez que Siegfrid se presentó ante esta reina, se hizo pasar por vasallo de Gunther, con intención de ayudarle a conseguirla por esposa. Lograr la mano de Brünhild suponía un reto para sus pretendientes, puesto que ella prometió que sólo se casaría con aquel guerrero que la superara en unas pruebas físicas, en las que hasta el momento nadie había conseguido vencerla. Gunther le

${ }^{8}$ Estrofa 1596. (Bartsch/Boor, 1999: 480). 
pide auxilio a Siegfrid, y éste, cubriéndose con su capa mágica que le hacía invisible, ayuda a Gunther a superarlas todas.

Brünhild consiente en casarse con Gunther totalmente engañada, y por tanto, la mentira de que Siegfrid es un vasallo de su marido se mantendrá en el futuro, y será el detonante de una cadena de sucesos que le van a llevar a su final: Brünhild va a creer siempre en la inferioridad social de Siegfrid. Por eso, se extrañará cuando nada más llegar a Worms se entere de que Kriemhild, una reina de alto rango y hermana del rey Gunther, va a casarse con Siegfrid, que es supuestamente de rango inferior. Según el derecho medieval, si Krimhield se casa con un hombre de tal condición, pierde sus privilegios y su reputación. Por eso Brünhild le pide explicaciones a Gunther. Como éste no se las da, ella le niega la consumación del matrimonio en la noche de bodas. Gunther intenta tomarla por la fuerza y entonces "Daz er ír die wât zerfuorte, diu vrouwe iz groezlîchen rach" ". Brünhild es más fuerte que Gunther y lo domina fácilmente colgándolo de la pared durante toda la noche. $\mathrm{Al}$ día siguiente Gunther le cuenta lo ocurrido a Siegfrid y una vez más éste promete ayudarle. Esa misma noche, el héroe se pone la capa invisible y haciéndose pasar por Gunther, lucha contra Brünhild y la somete. A partir de entonces, y totalmente engañada, la reina se vuelve sumisa y pierde su fuerza física.

Este hecho sin embargo no queda impune. Con el paso de los años Brünhild sigue extrañada del hecho de que si Siegfrid es vasallo de Gunther, por qué éste no le rinde tributo ni le visita. Así que pide que los invite a él y a Kriemhild a la corte de Worms. Gunther lo hace con gusto, y entonces es cuando tiene lugar un conflicto entre las dos reinas, que será el desencadenante del desastre.

Estamos ante una época en la que el rango y la posición pública son el atributo más importante de una persona, y en el caso de las dos reinas, se mide por el poder de sus maridos. Así pues, el problema surge cuando ambas no se ponen de acuerdo en cuál de los dos, si Gunther o Siegfrid, es más poderoso. Lógicamente Brünhild, que sigue creyendo que Siegfrid es vasallo de Gunther, sostiene que es su marido. Pero aunque Siegfrid había mentido en su momento jugando con su posición social, Kriemhild no está dispuesta a ser rebajada en público por una mentira -ella sí conoce la verdad-. Tras no ponerse de acuerdo en el rango, que es un asunto público, Kriemhild comienza a discutir en el ámbito privado elogiando la gallardía y las cualidades de su marido, mientras que Brünhild sigue insistiendo en el plano político. Así la pelea se incrementa hasta que Kriemhild responde delante de todo el mundo a la injuria pública de Brünhild (que sigue creyendo que Siegfrid es un vasallo) con una ofensa en el ámbito privado: fue Siegfrid, y no Gunther quien la dominó en la noche de bodas.

El mal ya está hecho y Brünhild se siente ultrajada. Por lo que Hagen, vasallo de Gunther, decide vengarla y restaurar su honor matando a Siegfrid, que ha sido el responsable de su desgracia. Para ello y mediante engaños, consigue que Kriemhild le revele cuál es el punto débil de su marido. Se sabe que al bañarse en la sangre del dragón le cayó una hoja de tilo en la espalda y esa zona de su cuerpo quedó excluida de las propiedades inmunes de la sangre. Finalmente se realiza la venganza de Brünhild y Siegfrid cae muerto, aunque como dice el propio narrador, no sin antes haber deseado poder vengar él mismo esta afrenta.

\footnotetext{
${ }^{11}$ Estrofa 671d. (Bartsch/Boor, 1999: 206).
} 
Tras la muerte de Siegfrid, los Nibelungos y el propio Sigmund cogen las armas rápidamente para vengar la muerte de su señor y del ser querido. Pero Kriemhild les detiene porque al estar en tierra burgunda, las huestes de Gunther son mayores y el ejército del padre de Siegfrid perdería con toda probabilidad. El viejo rey decide volver a su patria, y los Nibelungos declaran que volverán en son de guerra cuando sepan quién ha sido el culpable.

Aunque Hagen puede vengar a su reina Brünhild, tiene que seguir unas normas que no cumple. En primer lugar, Gunther y Hagen han matado a Siegfrid en secreto y a traición. Además, Hagen deja el cuerpo de Siegfrid ante la puerta de Kriemhild sin nadie que se responsabilice del hecho. Lo correcto hubiera sido enseñar públicamente el cuerpo ante todos y dejar que lo lloraran. Por eso nada más ver el cadáver, Kriemhild sospecha con razón quién lo ha hecho y por qué.

Después de esto Brünhild ya no aparece más en la obra, puesto que la función de este personaje era preparar la venganza de Kriemhild, verdadero motor de todo el Cantar.

\subsection{La venganza de Kriemhild}

Kriemhild es un personaje sumamente interesante, cargado de contrastes. Está presente en el poema desde la primera aventura, y se la describe con dos atributos fundamentales: una belleza deslumbrante y un comportamiento demoníaco.

Kriemhild es la mujer más hermosa de la tierra, motivo del suspiro de muchos caballeros y adorno para las demás mujeres. Crece en la fastuosa corte de Worms bajo la tutela de sus hermanos, y viviendo así es cuando tiene un sueño que vaticina todo lo que acontecerá en la obra: el hombre del que se va a enamorar morirá pronto. Sin embargo ella, que es consciente de su belleza, piensa seguir mucho tiempo sin casarse, porque no quiere sufrir por amor. No obstante su vida cambiará cuando conozca a Siegfrid.

Es importante detenerse en la imagen que el narrador utiliza para describir cómo se apareció Kriemhild con su séquito ante Siegfrid por primera vez:

Nu gie diu minneclîche, alsô der morgenrôt

tuot ûz den trüeben wolken. (...)

Jâ lûhte ir von ir waete vil manec edel stein.

ir rôsenrôtiu varwe vil minneclîchen scein.

ob iemen wünscen solde, der kunde niht gejehen,

daz er ze dirre werlde het iht scoeners gesehen.

Sam der liehte mâne vor den sternen stât, des scîn sô lûterlîche ab den wolken gât, dem stuont si nu gelîche vor maneger frouwen guot $(\ldots)^{12}$.

Irradia belleza, como si de la luz de la aurora se tratara, y es esta una imagen plástica muy propia de la literatura caballeresca. Además, y aunque también se alaba la hermosura de Brünhild, el narrador le otorga a Kriemhild siempre una belleza superior.

Kriemhild ha sido educada en los modales de la corte, como lo prueban en la primera parte del Cantar el correcto recibimiento a los invitados, y el hecho de que antes del asesinato obedeciera en todo a sus hermanos a los que respetaba y amaba. El narrador llega a presentarla como una doncella inocente, y la propia Brünhild alabará sus buenas maneras.

${ }^{12}$ Fstrofac 281-783 /Rarterh/Ranr 1000. onl 
Lógicamente, Kriemhild tiene un gran número de pretendientes a los cuales es inaccesible. No es una doncella fácil de conseguir, porque además Kriemhild es una reina poderosa de la misma condición que Siegfrid. De hecho, cuando se marcha con él a Xanten, ella reclama los vasallos que le corresponden por herencia. Además, cuando la madre de Siegfrid muere, ella se convierte en señora absoluta de los Países Bajos. Va siempre acompañada de un gran número de doncellas ricamente ataviadas, y ella misma rezuma fastuosidad. Por lo tanto, su rango y el de su marido están por encima de los de Gunther, y es por esta razón por la que no está dispuesta a rebajar sus títulos ante nadie y mucho menos por mor de una presuposición falsa.

Sus sentimientos positivos son el amor hacia su hermano Giselher y hacia su marido Siegfrid. La primera vez que Kriemhild ve al rey de los Países Bajos es a través de una ventana, y se convierte en amor a primera vista. Sin conocerse, ambos piensan el uno en el otro, y ella teme por él cada vez que parte para alguna expedición. Así están un año sin verse, hasta que Gunther decide dársela a Siegfrid en matrimonio. En su relación, Kriemhild no es la mujer inaccesible y fría del Minnesang, ya que es un amor recíproco, estando además orgullosa de él, y alabando sus dotes de guerrero y amante. Es un amor correspondido y sincero, que desde el principio ha sido buscado por los dos. Ya en la noche de bodas se reafirman sus sentimientos, donde Kriemhild se convirtió para Siegfrid en la única mujer para él ${ }^{13}$.

La muerte que separa a los amantes es siempre dolorosa. De tal manera, que Kriemhild también desea morir, ya que entre ambos hay una unión indisoluble a la que Kriemhild va a ser fiel durante el resto de su vida, llorándole y planeando su venganza, siendo el matrimonio con Atila un trámite más para llevar a cabo este objetivo y no una unión por amor.

Muchos críticos han creído ver una evolución en el carácter de Kriemhild. ¿Cómo es posible que una doncella adornada de todas las virtudes propias de una dama cortesana albergue en sí tales sentimientos de venganza que la hagan ser tachada de vâlandinne $?^{14}$. De esta manera, desde el momento en que invita a los burgundos ${ }^{15}$, a los que considera sus enemigos, Kriemhild comenzará a tener otros atributos mucho más negativos. Su comportamiento es malvado, porque por su culpa van a morir muchos hombres inocentes y buenos caballeros. El narrador achaca la causa a que probablemente Kriemhild tuvo una mala influencia del demonio. Todos temen su espantosa cólera. Volker la considera una mujer de conducta alevosa ${ }^{16}$, Hagen la llama "la aviesa Kriemhild"17, y él mismo junto con Dietrich, "mujer endemoniada"18.

Los motivos de la venganza de Kriemhild son dos: que los responsables de la muerte de su marido sufran su castigo, y la recuperación del tesoro de los Nibelungos.

\footnotetext{
${ }^{13}$ Estrofa 629 (Bartsch/Boor, 1999: 192).

${ }^{14}$ Estrofa 1748 (Bartsch/Boor, 1999: 526).

${ }^{15}$ Estrofa 1390 (Bartsch/Boor, 1999: 420).

${ }^{16}$ Estrofa 1773: “... diu uns âne triuwe inz lant geladet hât ...”. (Bartsch/Boor, 1999: 534).

${ }^{17}$ Estrofa 1853: “argen Kiremhilden”. (Bartsch/Boor, 1999: 558).

${ }^{18}$ Estrofas 1748 y 2371: "vâlandinne". (Bartsch/Boor, 1999: 526) y (Bartsch/Boor, 1999: 712).
} 
La necesidad de venganza de Kriemhild se despierta tras la muerte de Siegfrid, pero no puede vengarse por sí sola. Al igual que Brünhild, por el hecho de ser mujer, necesita a alguien que la ayude. Tras la muerte de Siegfrid su posición pública se reduce en Xanten, siendo su suegro demasiado débil para efectuarla. Por otro lado, sus hermanos no van a ayudarla porque son los que han urdido el complot de asesinato.

En esta búsqueda de satisfacción, no sólo está en juego el prestigio y la reputación ofendidas, sino que Kriemhild también se venga por amor a su marido. Tras la muerte de su marido, en vez de marcharse de Worms, Kriemhild inexplicablemente se queda allí, diciendo que desea estar al calor de su familia. Se reconcilia aparentemente con ésta, y además permite que traigan a Worms el tesoro de los Nibelungos.

Siegfrid regaló esta fortuna a Kriemhild al día siguiente de la noche de bodas, convirtiéndose, además de en una forma de abastecimiento económico, también en un símbolo del reconocimiento del estatus de la esposa. Por eso Kriemhild puede contar con este tesoro que le pertenece, y que le sirve para mantenerse económicamente. Una vez traído a Worms, empieza a repartirlo con generosidad. Esto disgusta a Hagen, que cree que con tantas dádivas Kriemhild, que todavía piensa en Siegfrid, está ganando adeptos para ejecutar su venganza. Por esta razón, Hagen se apodera del tesoro y lo arroja al Rin.

Así pues, al dolor por la muerte de Siegfrid se le suma esta nueva humillación, en la que Kriemhild va a hacer especial hincapié. Cuando los burgundos llegan a la tierra de Atila y Kriemhild sale a recibirlos, lo primero que hace es preguntar por el tesoro, como si ya no se acordara de Siegfrid. Y es que para la reina el tesoro ya no tiene un valor meramente material, sino que al ser un regalo de Siegfrid, también es una parte de él y un recuerdo suyo. Por un lado, es un símbolo de poder y soberanía y por otro, del propio Siegfrid, y el tenerlo es una prueba de fidelidad hacia el muerto. Así, la decapitación de Hagen después de que no le hubiera querido decir dónde estaba el tesoro es el crêrre de un plan de venganza escalonado, que está guiado por el ultraje de su honor, al igual que su amor a Siegfrid.

Los trece años en Worms llorándole son un acto de resignación hasta que finalmente ve posibilidades casándose con Atila. En principio ella se niega a aceptar la proposición de matrimonio, porque el rey de los hunos es un pagano, y el matrimonio entre cristianos y gentiles en la Edad Media era nulo, pues el bautismo era condición necesaria para participar en cualquier sacramento. Sin embargo, Kriemhild accede a casarse con un pagano -teniendo en cuenta la vergüenza que supone para una dama de la corte cristiana-, ya que así podrá desligarse de la tutela de sus hermanos y ser independiente. Según las leyes germánicas y luego medievales, la mujer no era un ser responsable, por lo que debía estar siempre bajo la tutela de algún varón.

De todas formas, ella es recelosa, y sólo acepta la propuesta al recibir la promesa de Rüdiger de que va a conseguir que Atila se convierta. Se celebran las bodas y durante trece años todo parece rezumar felicidad: Kriemhild se comporta como una reina modélica, superando a la difunta esposa de Atila, y le da un hijo, Ortlieb, que se convierte en el heredero del trono. Sin embargo, la reina sigue pensando en una venganza insatisfecha y convence a su marido para que invite a los burgundos al país de los hunos. El mismo narrador entonces será quien diga: "ich waene der übel vâlant Kriemhílde daz geriet, / daz 
sie sích mit friuntschefte von Gunthere schiet, / den si durch suone kuste in Búrgónden lant. / Do begónde ir aber salwen von heizen trehen ir gewant" 19 .

Cuando los burgundos reciben la invitación deliberan muy cuidadosamente qué hacer, porque todos saben que Kriemhild todavía quiere vengarse. Llegan por fin a la corte huna, y son recibidos con todo tipo de honores por parte del rey. Sin embargo, ya desde que sale a saludar a los recién llegados, Kriemhild comienza a discriminar a los invitados: de entre sus parientes, sólo saluda a su hermano Giselher. Esto pone en guardia a Hagen, que está dispuesto a luchar si hace falta. Ella se dirige a él, le acusa y le provoca en público de manera que los caballeros hunos salgan-en su defensa y ataquen a Hagen, pero éste no se inmuta. Es más, no se levanta ante Kriemhild en señal do respeto y le muestra la espada Balmung, propiedad de Siegfrid, ante cuya presencia Kriemhild comienza-a llorar. A medida que avanza el diálogo la tensión es cada vez más fuerte, hasta llegar a un punto en el que Hagen, orgulloso, confiesa su venganza y la muerte de Siegfrid sin temor ${ }^{20}$.

Tras una incursión infructuosa de una partida de hửnos a las habitaciónes de los burgundos, Kriemhild nuevamente envía a más caballeros con los que comienza una batalla descomunal que dura tres días, y en la que los burgundos vivos beben de la sangre de los caídos para retomar fuerzas. Desesperada por los intentos fracasados, Kriemhild manda incendiar la sala. La lucha está en un pånto culminante, pasando ya a la lidia entre amigos, donde se producen sonflictos entre los lazos de amistad y los juramentos de vasąllaje.

Mientras que Brünhild sí consiguió terminar con éxito su venganza, Kriemhild es ella misma la que tiene que ejecutarla por no encontrar caballeros que lo hagan de manera incondicional. A pesar de prometer grandes riquezas, no ençuentra a nadie que desde el primer momento quiera ayudarla a ejecutar la venganza en su lugar, como Hagen hizo con Brünhild. Por eso, a Kriemhild no le queda más remedio que realizarla ella misma decapitando a Hagen con la espada de Siegfrid. La obra concluye con este acto de desesperación que es castigado a su vez cuando un vasallo de Dietrich mata a Kriemhild.

\section{CONCLuSión}

Así pues la venganza, considerada en la tradición germánica como un placer de los dioses, y en sociedades primitivas como una medida de justicia, aparece en el Cantar de los Nibelungos encarnada en su protagonista Kriemhild con connotaciones negativas. Para ella es un deber sagrado vengar a Siegfrid y por eso invierte toda su vida en este objetivo. Además, ya no es una simple ofensa, sino que como viuda consumida por el dolor, Kriemhild quiere hacer pagar su culpa a los responsables del daño. A esto se le une también la humillación por el robo del tesoro de los Nibelungos, que por herencia le correspondía. De esta manera y a simple vista, ella está impartiendo justicia por su propia mano. Sin embargo, hay multitud de elementos en la obra que al mismo tiempo dan a entender que la actitud de Kriemhild es rechazable.

De esta manera, Kriemhild rompe la costumbre cortesano-caballeresca con su ansia desmedida de venganza. Persiste en ella a pesar de haberse reconciliado con su hermano, y eso va contra las creencias cristianas, motivo por el cual Hagen la llama "vâlandinne"21.

\footnotetext{
${ }^{19}$ Estrofa 1394. (Bartsch/Boor, 1999: 420).

${ }^{20}$ Estrofa 1791. (Bartsch/Boor, 1999: 538).

${ }^{21}$ Estrofa 2371. (Bartsch/Boor, 1999: 712).
} 
Kriemhild también transgrede las propias leyes germánicas, en donde el derecho de venganza de sangre está limitado sólo al asesino, y no contra parientes o inocentes. Además, la reina no está movida por un simple sentimiento de justicia, sino por el odio, de tal manera que intenta vengarse de sus invitados en secreto, y se niega a concederles un último perdón cuando son todavía rehenes.

Lo más fascinante del poema consiste en ver cómo Kriemhild lleva a cabo su venganza, que no sólo es el eje en torno al cual gira su existencia sino también el motor de la obra. Aunque la saga pertenece al mundo germánico, los elementos cristianos se entremezclan transmitiendo al final un mensaje apropiado para la mentalidad del caballero cristiano de la época de los Staufer, y no del guerrero germánico de la época de las grandes migraciones. Así, en el Cantar de los Nibelungos sólo sobreviven a la gran destrucción del pueblo burgundo los personajes que precisamente representan el ideal de vida cortesanocaballeresco: el rey Atila, Dietrich y su vasallo Hildebrando. De esta forma, la mesura y la armonía defendidas a lo largo de la obra poseen un componente cristiano de piedad y misericordia, y es lo que sobrevive y realmente vale en los nuevos tiempos de la Plena Edad Media, cuando el poema es plasmado por escrito.

El decir que el Cantar de los Nibelungos es una de las obras cumbres de la literatura universal no es vano. Ciertamente, en sus 2379 estrofas se respira una tensión dramática que alcanza límites inimaginables y que consiguen que la acción corra rauda hacia un desenlace final trágico, que ya se va gestando desde las primeras estrofas del poema, y que aparece envuelta en un ropaje de cultura mágica germánico-pagana con gotas de un cristianismo civilizado y cortesano que es que el que le infunde la nota de distinción y el verdadero mensaje a la obra. Es la historia de una venganza abrumadora y desproporcionada para el mundo cristiano en el que se concibe, pero que al mismo tiempo dota a esta epopeya de una grandeza que aún en la actualidad sorprende y sobrecoge.

\section{BIBLIOGRAFÍA}

BARTSCH, Karl/BOOR, Helmut de, Das Nibelungenlied. Mhd/Nhd. Stuttgart, Reclam,1999.

BERMAN, Harold J., La formación de la tradición jurídica de Occidente. Méjico, Fondo de Cultura Económica, 1996.

Cayo CORNELIO TÁCITO, La Germania (texto latino y castellano con notas). Valladolid, Librería Santarén, 1940.

Duden Etymologie. Herkunftswörterbuch der deutschen Sprache. Band 7. Mannheim, Dudenverlag, 1989.

DÜRRENMATT, Nelly, Das Nibelungenlied im Kreis der höfischen Dichtung. Berna, 1945.

Enciclopedia universal ilustrada europeo-americana. Barcelona, Espasa, 1934.

HOLZHAUER, Antje, Rache und Fehde in der mittelhochdeutschen Literatur des 12. und 13. Jahrhunderts. Göppingen, Kümmerle Verlag, 1997.

KLEIN, Christoph, Wenn Rache der Vergebung weicht. Theologische Grundlagen einer Kultur der Versöhnung. Göttingen, Vandenhoeck \& Ruprecht, 1999. 
KROGMANN, Willy, Der Dichter des Nibelungenliedes. En: Philologische Studien und Quellen, 11. Berlin, Erich Schmidt, 1962.

LORENZO CRIADO, Emilio (ed.), Cantar de los Nibelungos. Madrid, Cátedra, 1994.

Sagrada Biblia. Versión directa de las lenguas originales. Por Eloino Nacar Fuster / Alberto Colunga Cueto, O.P.. Madrid, Biblioteca de autores cristianos, 1983.

SCHRÖDER, Werner, "Die Tragödie Kriemhilts im Nibelungenlied". ZfdA 82 (1948/50), pp. 41-80/123-160.

SIMON, Elisabeth, Höfisch-ritterliche Elemente im Nibelungenlied. Ein Beitrag zur Frage nach der sozialen Herkunft des Verfassers. Duisburg, Carl Lange, 1927.

STEINMETZ, S.R., Ethnologische Studien zur ersten Entwicklung der Strafe. Leiden, Doesburgh, 1892.2 vol.

WESEL, Uwe, Geschichte des Recht. Von den Frühformen bis zur Gegenwart. München, C.H.Beck, 2001. $2^{\mathrm{a}}$ ed. 